\title{
From Load Estimation to Performance Estimation-From Model-Scale Test to Full-Scale Test: With Special Interest in Asian Region
}

\author{
Yukio Tamura, ${ }^{1,2 *}$, Kazuyoshi Nishijima ${ }^{3}$, Masahiro Matsui $^{2}$, Pham Van Phuc ${ }^{4}$ and \\ Qingshan Yang ${ }^{1}$
}

${ }^{1}$ School of Civil Engineering, Beijing Jiaotong University, Beijing, China, ${ }^{2}$ Wind Engineering Research Center, Joint Usage/ Research Center Program, Tokyo Polytechnic University, Tokyo, Japan, ${ }^{3}$ Disaster Prevention Research Institute, Kyoto University, Kyoto, Japan, ${ }^{4}$ Research Institute, Shimizu Corporation, Tokyo, Japan

OPEN ACCESS

Edited by:

Gregory Alan Kopp, University of Western Ontario,

Canada

Reviewed by:

Suren Chen,

Colorado State University, USA Arindam Gan Chowdhury, Florida International University, USA

*Correspondence: Yukio Tamura yukio@arch.t-kougei.ac.jp

Specialty section: This article was submitted to Wind Engineering and Science, a section of the journal Frontiers in Built Environment

Received: 01 November 2016 Accepted: 19 January 2017

Published: 14 February 2017

Citation:

Tamura Y, Nishijima K, Matsui $M$, Phuc PV and Yang Q (2017) From Load Estimation to Performance Estimation-From Model-Scale Test to Full-Scale Test: With Special Interest in Asian Region.

Front. Built Environ. 3:8. doi: 10.3389/fbuil.2017.00008
This paper first discusses the current status of natural hazard-induced disasters, with special focus on devastating wind-related disasters in the Asian region. The importance of the combined effects of wind and water hazards, the importance of performance of cladding and components in wind-resistant design of buildings, and deterioration of metal roofing systems of long-span structures mainly caused by fatigue of fixing joints due to daily solar heating effects are demonstrated. Some human errors caused by lack of attention to aerodynamic and structural behaviors are also indicated. Then, psychological impacts and social impacts are discussed, and common underestimation of social impacts of wind-induced disasters on society is pointed out. The main reason for repeated wind-induced damage is lack of information on the real performance of claddings, components, and main frames under wind actions. The demand and necessity for full-scale tests are emphasized, aiming to check the performance of building and structural systems under realistic and controlled conditions of extremely strong actions of wind, rain, snow, fire, solar heating, and so on. Finally, the academic and social significance of the full-scale storm simulator is discussed.

Keywords: full-scale storm simulator, wind-related disaster, tropical cyclone, tornado, economic loss, human loss, psychological impact, social impact

\section{INTRODUCTION}

Human beings spend their daily lives within the range of the atmospheric boundary layer (ABL), in which the air flow is affected by friction due to ground surface roughness. The air flow within this range is generally called wind, and strong wind occasionally causes severe damage to infrastructures and people due to its aerodynamic effects. However, weak- or medium-level wind can cause severe vibrations of structures or members and can have serious environmental impacts on human society, 
such as air pollution problems and thermal effects. There are several wind climates that cause damage to buildings and structures, including monsoons, frontal depressions, tropical cyclones, gust fronts, downbursts, tornadoes, dust devils, katabatic winds, lee waves, and so on. Tropical cyclones are intense cyclonic storms that occur over tropical oceans, mainly in summer and early autumn. They are known as typhoons in the West Pacific Ocean region, cyclones in the Oceania and the Indian Ocean regions, and hurricanes in American and Caribbean regions, with slightly different definitions. The diameters of tropical cyclones, defined by the isobar of $1,000 \mathrm{hPa}$, range from around 100 to $2,000 \mathrm{~km}$, but are usually of the order of several $100 \mathrm{~km}$. The thickness of the atmosphere involved is about $10-12 \mathrm{~km}$, and a roughly circular "eye," or "hot tower," is formed in the storm's center. It should be noted that tropical cyclones are often accompanied by severe local storms (SLSs) such as tornadoes and downbursts. Almost all devastating wind-induced disasters result from combined effects of strong wind and accompanying water hazards due to heavy rain and storm surge. The social impacts of these "wind-related" disasters have been some of the most severe in our human society (Tamura et al., 2012). At the bottom of the $\mathrm{ABL}$, human activities are also seriously disturbed by other meteorological phenomena such as snow, hail, extremely hot/ cold temperature, and so on, and winds always have strong impacts on those phenomena. Fire hazards also occur at the bottom of the ABL either as meteorological/natural hazards or man-made hazards, and they cannot be treated without wind effects.

The risk of future disasters continues to escalate with population shifts toward urban centers, and the impending threat of their increased intensity and frequency as hypothesized by potential climate change. Urbanization has also led to the deterioration of regional and global environmental quality with a far reaching impact on public health. Not only accidentally occurring extremely strong wind events but also serious environmental problems in weak- or medium-level wind conditions should be treated as hazards causing severe disasters in our human society. The latter are invisible and long-lasting disasters and can be more dangerous than the former. This calls for a sustainable society that emphasizes reduced energy consumption and improved environmental quality (Tamura et al., 2012).

The Science Council of Japan (SCJ) selected 207 projects as the Academic Master Plans 2014 of Large Research Facilities and Large Research Projects (Master-Plan-2014, hereafter) (SCJ, 2014). In addition, the SCJ especially selected the 27 most important and most urgent projects from among the 207 projects in the Master-Plan-2014 as Priority Policy Projects (PPPs). The SCJ belongs to the Cabinet Office, Government of Japan, and consists of 210 Council Members and 2,000 Members from 30 academic fields including civil engineering and in various areas such as liberal arts, social sciences, life sciences, physical sciences, chemical sciences, and engineering including civil engineering. The majority of the 27 selected PPPs are from areas in the life and physical sciences, and a few are from engineering. The "full-scale storm simulator (FSSS) and Meteorological Hazards Science Park (MHSP)" proposed by the first author of this paper has been selected as one of the 27 PPPs.
This paper emphasizes the importance, efficiency, and necessity for full-scale facilities for disaster risk reduction (DRR), especially in the Asian region.

\section{DEVASTATING WIND-RELATED DISASTERS (WRDs) ESPECIALLY IN ASIAN REGION}

Typhoon Vera attacked the central part of Japan in September 1959. Its maximum recorded peak gust was $55.3 \mathrm{~m} / \mathrm{s}$, and the Japan Meteorological Agency estimated $75 \mathrm{~m} / \mathrm{s}$ as the maximum peak gust from the lowest pressure recorded of $895 \mathrm{hPa}$. Fatalities and missing numbered 5,098, and the majority were caused by the storm surge. We should emphasize the combined effects of wind and water hazards.

In 1970, Cyclone Bhola (see Figure 1) struck East Pakistan. The highest record of 10-min mean wind speeds was $57 \mathrm{~m} / \mathrm{s}$, and the lowest pressure was $966 \mathrm{hPa}$. Economic loss was estimated at 460 million USD, which is relatively high considering the GDP of this country. However, more seriously, a shocking number of fatalities and missing were reported, 300,000-500,000, of which there is no exact information. The majority of fatalities and missing were caused by the storm surge, again resulting from the combined effects of strong wind and water hazards. It is said that one of the reasons, why East Pakistan became independent from West Pakistan in 1971, was insufficient support from West Pakistan for this devastating disaster. Thus, the hot spots of human losses are in developing countries, especially in the South Asian region.

Typhoon 7513 recorded a maximum peak gust of $67.8 \mathrm{~m} / \mathrm{s}$ at Hachijo Island, Tokyo, Japan, in 1975. The effects of topography and impacts of wind-borne debris were significant as seen in Figure 2.

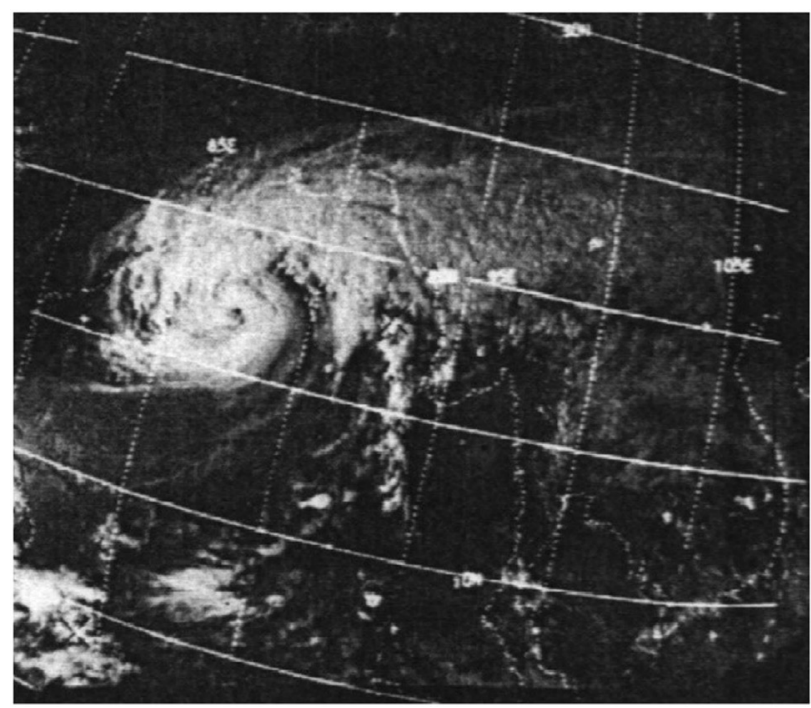

FIGURE 1 | Image of Cyclone Bhola, November 11, 1970 (NOAA, Wikipedia) 


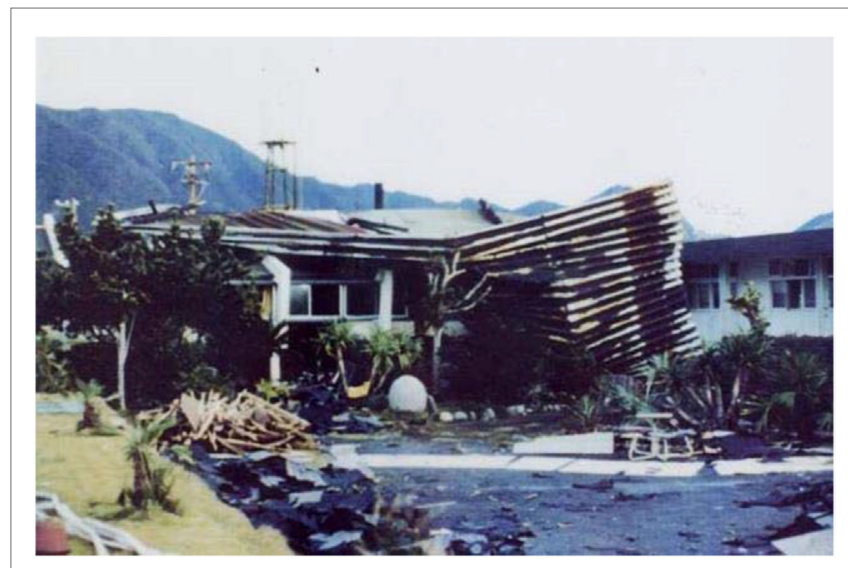

FIGURE 2 | Debris impacts, Typhoon 7513 at Hachijo Island, Tokyo, Japan.

One of the most serious cases of damage in terms of fatalities due to tornados happened in Manikganj, Bangladesh, in April 1989 as shown in Figure 3. Fatalities unofficially numbered $800-1,300$ (DMB, 2009). Based on the statistics of 36 years from 1961 to 1996 , the total number of fatalities due to tornados and SLSs in Bangladesh were 10,766, averaging around 300 people killed every year.

Examples of typical recent damage to long-span roof structures in Japan in 2004 are shown in Figures 4-7. Ten typhoons made landfalls on the Japanese main islands in 2004, which was a special year, while three or fewer typhoons make landfalls annually on average.

Figure 4 shows damage to roof plates of SPring- 8 in Hyogo, Japan, due to two typhoons in 2004. Bolts connecting a two-layer folded steel plate roofing system to the main frames of the building had been damaged by fatigue effects due to daily solar heating before two typhoons struck this area. The peak gusts recorded at the site during these two typhoons, Chaba and Songda, were 39 and $36 \mathrm{~m} / \mathrm{s}$, respectively. These were far below the corresponding design wind speed, which was around $60 \mathrm{~m} / \mathrm{s}$ at $10 \mathrm{~m}$ high over open flat terrain. One side of the upper folded steel plate was engaged between the saddle and the clamp metal and crimped. The opposite side covered the end of the next upper folded steel plate on the clamp metal, and the upper folded steel plates were not fixed to prevent rain leakage and to allow the upper folded steel plates to slide along the roof span. This was expected to deal with the extension and contraction of the folded steel plate due to temperature change. This building was a special experimental facility having a $1.5-\mathrm{km}$-long perimeter and a $30-\mathrm{m}$ roof span, and contained ultra-precision devices and instruments, which did not allow building deformation. The number of striations observed in the bolts closely corresponded to the number of days after building construction in 1996. This suggests the need for careful design of the building's cladding and components, as well as emergency inspections of this kind of structure and periodic inspections every 5-10 years to maintain the quality of the roof system. Structural designers are mainly concerned with structural frames and give less attention to cladding and components.

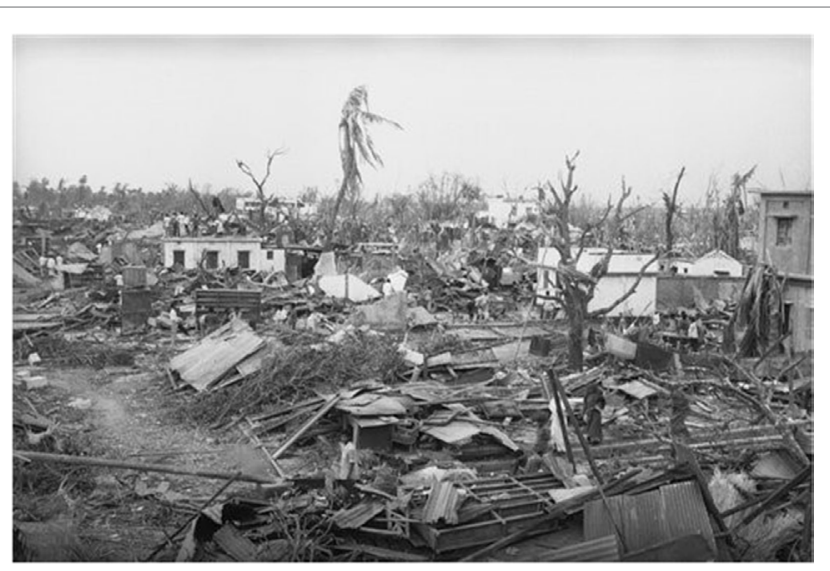

FIGURE 3 | Tornado damage in Manikganj, Bangladesh, April 1989.1

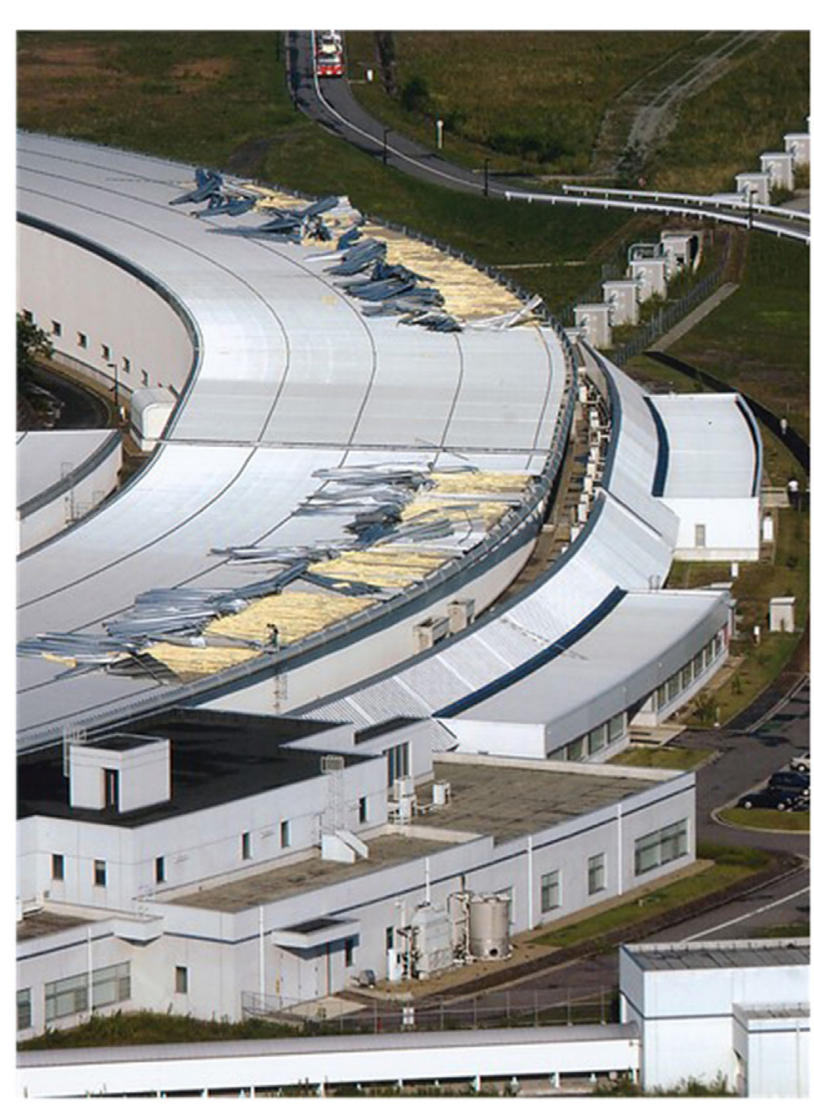

FIGURE 4 | Damage to two-layer folded steel plate roofing system of SPring-8, Riken, Hyogo, Japan, by Typhoon Chaba and Typhoon Songda, 2004 (by Kyodo: Tamura et al., 2005).

An efficient and feasible system to guarantee the performance of claddings with close collaboration between structural designers, manufacturers, and constructors should be established.

${ }^{1}$ Rahman, M. S. (2014). Bangladesh Disaster Preparedness Center (BDPC), Personal Communication. 
Figure 5 shows damage to a dome structure with wooden truss frames in Shimane, Japan, due to Typhoon Songda. The membrane was made of glass fibers with a Teflon coating. In order to create the beautiful V-shape waves seen in Figure 5, outer cables are used. However, dust had accumulated between the outer cables and membranes, and their surfaces had been continually rubbing each other due to micro-tremors by ambient excitations. As a result, the coated upper surface of the membrane had already been damaged before the typhoon excitation.

Figures 6 and 7 suggest a similar situation of roof cladding systems to Figure 4 due to solar heating and resultant fatigue effects on connecting bolts and elements as well as less attention to periodic maintenance. It is especially ironical that the upstream non-engineered traditional house survived without serious damage but the steel roof sheets of the engineered downstream school gymnasium were significantly damaged, as seen in Figure 7. This demonstrates that the roof sheets of the gymnasium had not been sufficiently fixed to the roof frame and had no resistance to suction forces. The reason for this can be attributed to deterioration over time, including fatigue effects.

In 2005, a single-layered lattice dome coal yard in Hualien, Taiwan, collapsed during Typhoon Haitang. The open-top structure has disadvantages from both aerodynamic and structural rigidity viewpoints, and the single-layered-dome system fosters structural instability. Hurricane Katrina caused serious human and economic losses to the US due to the combined effects of wind and water hazards. It has been reported that more than 2,500 people were killed, and 108 billion USD of damage was caused (Brunkard et al., 2008; Blake et al., 2011) also in 2005. Some damage to tall buildings reported by the media strongly suggested the importance of cladding design, especially window panes and roof cover sheets. Damage to the Louisiana Super Dome also suggested poor performance checking and maintenance of a roofing system similar to those shown

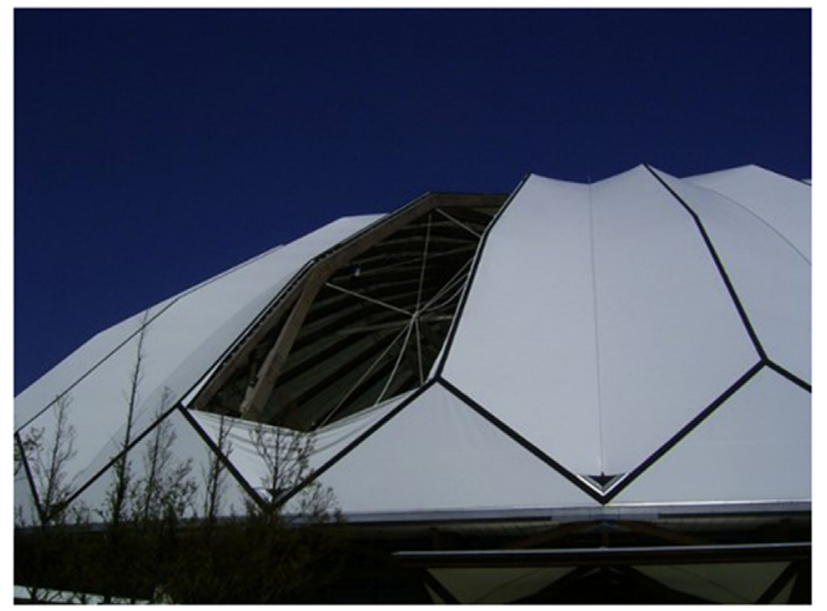

FIGURE 5 | Damage to membrane dome structure in Shimane, Japan, caused by Typhoon Songda, 2004 (Nishimura et al., 2005). in Figures 4,6 and 7. More importantly, many people evacuated to this dome and were forced to spend a very uncomfortable time inside it. This devastating disaster by Hurricane Katrina also suggested the serious combined effects of wind and water hazards.

Damage to cladding and components of a building is not limited to them. The situation inside the building can become terrible, as seen in Figure 8, which shows damage to window panes of a tall building in Houston, TX, USA, due to Hurricane Ike in 2008. Wind and rain got into rooms and destroyed almost everything, because design of materials and systems used inside rooms of buildings basically do not consider the effects of external forces (Brewick et al., 2009). Damage to furniture, equipment, and other articles contained inside this building stopped its required functions and caused significant economic losses.

In the same year, 2008, Cyclone Nargis made landfall in Myanmar and had significant impacts on the society, as seen in Figure 9. Fatalities and missing numbered more than 138,000, and economic losses were estimated at 10 billion USD (Zaw, 2009). There was a shocking number of human losses and a high ratio of economic losses to Myanmar's GDP. This devastating disaster was also due to the combined effects of wind and water hazards.

Figure 10 shows collapsed roof frames of a convention center in Leyte, the Philippines, due to Typhoon Haiyan in 2013. The Severe Weather Bulletin for Typhoon Haiyan by the National Disaster Risk Reduction and Management Council estimated the maximum peak gust at $76 \mathrm{~m} / \mathrm{s}$ from the lowest observed pressure. The highest maximum peak gust actually observed by PAGASA stations was $57 \mathrm{~m} / \mathrm{s}$ in the City of Roxas, Capiz. Although the meteorological records at Tacloban Airport Weather Station were lost in the 7-m-high storm surge, one of the officers gave evidence that the maximum $3 \mathrm{~s}$ peak gust he saw was $65-69 \mathrm{~m} / \mathrm{s}$, which coincided with the wind speed estimated from bent rebars at 65-70 m/s (Sanada et al., 2015). The mechanism of collapse of the steel trussed roof beams is estimated as follows. There are many ventilating openings on the windward wall as seen in Figure 10. So, the internal pressure became positive due to the air flow coming into the room, and the uplift force acting on the roof increased, especially near the roof's leading edge. Combined with the high negative pressure on the roof's external surface, the lift force acting on the upstream end significantly increased. It is not clear if the designer considered this exaggerating effect on the lift force of the roof frame, but the uplift could have been more than the design estimation. Then, the roof beams at the upstream end were lifted up and dropped from the beam supports. Many evacuated people were killed in this building, which had been designated as one of the evacuation places in case of disasters, as was the Louisiana Super Dome. The fatalities and missing were reported at 7,986 (NDRRMC, 2014).

As is easily understood, some of those failures were caused by more or less human error, and provided by poor knowledge and less attention to the performance of cladding and roofing systems. The necessity for FSSSs should be realized and emphasized. 


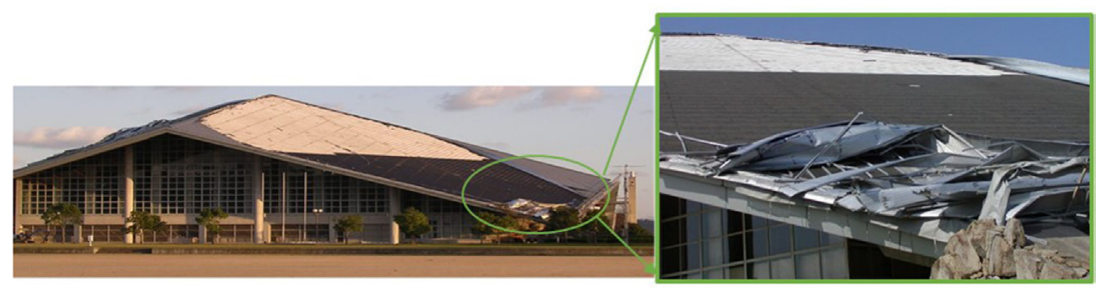

FIGURE 6 | Damage to steel roof sheets on a gymnasium in Kagawa, Japan, caused by Typhoons Dianmu, Namtheun, and Tokage, 2004 [courtesy of F. Nagao and H. Nishimura (Nishimura et al., 2005)]

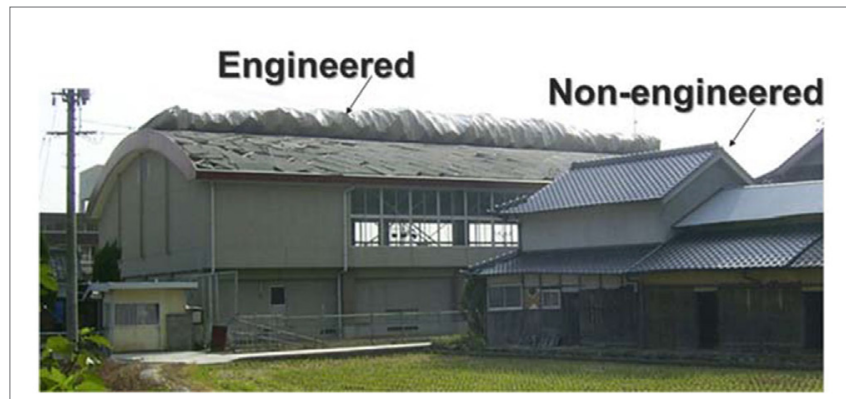

FIGURE 7 | Damage to a school gymnasium in Hiroshima, Japan, caused by Typhoon Tokage on October 20, 2004.

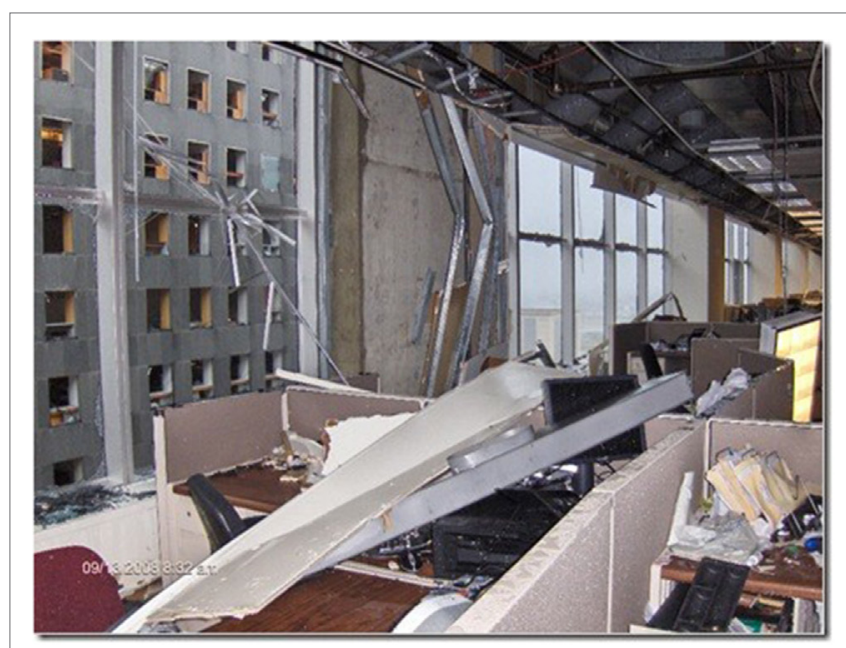

FIGURE 8 | Damage to a tall building in Houston, TX, USA, due to Hurricane Ike in 2008 (Brewick et al., 2009, courtesy of A. Kareem).

\section{PSYCHOLOGICAL IMPACT AND SOCIAL IMPACT}

As already discussed, Cyclone Nargis struck Myanmar on May 2, 2008, and left more than 138,000 dead or missing. However, this devastating disaster is only remembered by a few people. On the other hand, many people remember the $M_{\mathrm{w}} 7.9$ (USGS) Wenchuan Earthquake, which happened on May 12, 2008

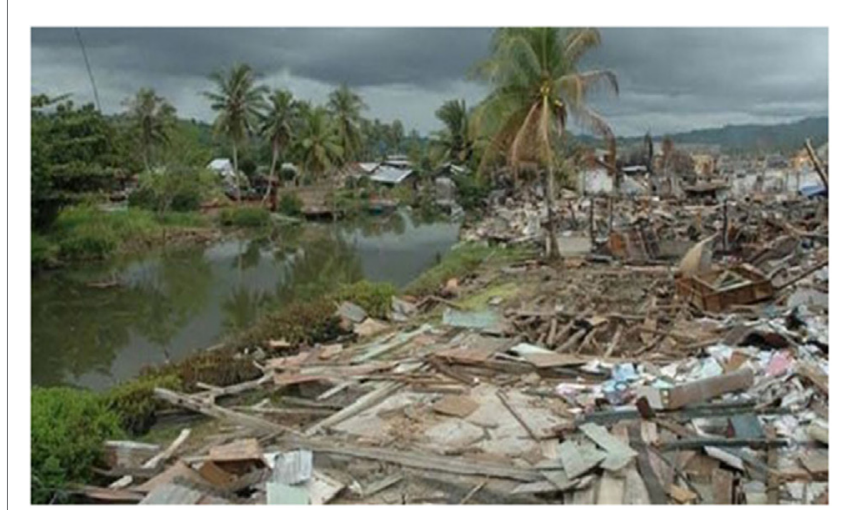

FIGURE 9 | Damage due to Cyclone Nargis in 2008, Ayeyarwaddy Division, Myanmar (Zaw, 2009).

in China, just 10 days after Cyclone Nargis. The Wenchuan Earthquake was also a devastating disaster and fatalities and missing numbered more than 87,000 , but the disaster caused by Cyclone Nargis is as serious as or more so than that caused by the Wenchuan Earthquake.

Similar phenomena have often been observed in Japan when comparing typhoon disasters and earthquake disasters. For example, the Niigata Prefecture Chuetsu Earthquake occurred on October 23, 2004, in Japan, and fatalities and missing numbered 68 , and the majority of Japanese people remember this disaster. However, almost nobody remembers a disaster that occurred 3 days prior to the Niigata Prefecture Chuetsu Earthquake. Typhoon Tokage struck the central part of Japan on October 20, 2004, and left 98 fatalities and missing. The media widely disseminated and reported the disaster scenes for 3 days after October 20, 2004. However, when the Niigata Prefecture Chuetsu Earthquake occurred, the media's interest, people's concern, and rescue by governments were all shifted and directed to the people and the area affected by the Earthquake, and people almost forgot about the disaster caused by Typhoon Tokage. In this case, the fatalities and missing resulting from Typhoon Tokage were also much larger than those resulting from the Niigata Prefecture Chuetsu Earthquake.

Why are people's reactions to tropical cyclone events and earthquake events different? One of the reasons may be attributed to the difference between the psychological impacts 


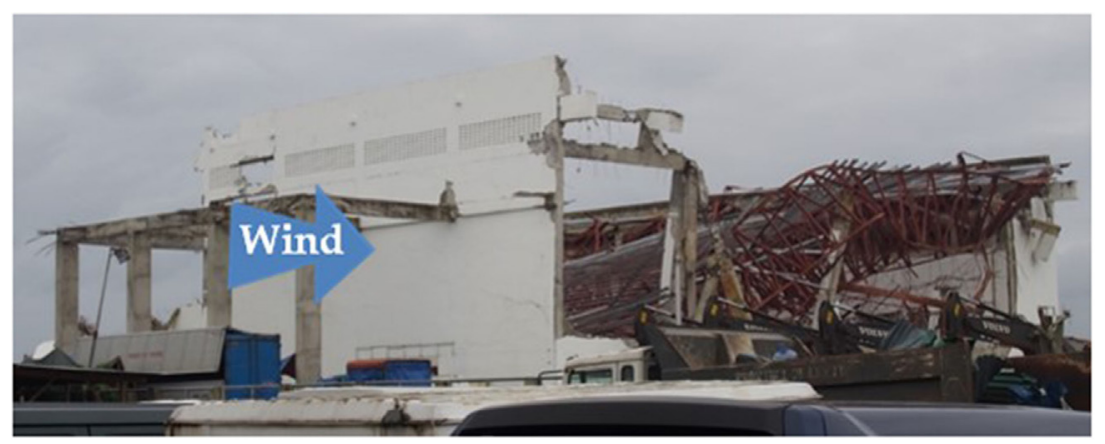

FIGURE 10 | Failure of a convention center in Leyte, The Philippines, due to Typhoon Haiyan in 2013.

of these two natural hazards. Earthquakes strike suddenly without warning, thus having intense psychological impacts on us. However, tropical cyclones and their tracks can be predicted with a sufficient lead time of 5 days or so, and we know the time of a tropical cyclone strike beforehand based on more or less established early warning systems. So, we know and can understand a tropical-cyclone-induced disaster's happening, and its psychological impact is not significant. However, earthquakes come randomly and occur unexpectedly. An earthquake-induced disaster is always surprising and is too abrupt to accept. This confusion magnifies its psychological impacts. Although it is obvious that the psychological impact is not proportional to the social impact, people tend to equate psychological impact and social impact. Biased coverage by media stimulates people and governments' reactions, and this kind of misunderstanding is widely made even in local and the central governments. Thus, people tend to consider that earthquake disasters are more significant than tropical-cyclone disasters and show less consideration for their actual social impacts. This can also result in a difference between research funds for the two academic fields.

There are similar misunderstanding between tornados and tropical cyclones. As for earthquakes, tornado occurrences are rarely predicted and strike suddenly. Thus, the psychological impacts of tornado disasters are much higher than those of tropical cyclone disasters. This of course differs from country to country, but damaged areas due to tornados are very limited compared to those due to tropical cyclones. The damaged area caused by a tornado is around $0.16 \mathrm{~km}^{2}$ on average in Japan (Niino et al., 1997). The average damaged area caused by a landfall typhoon in Japan is not clear, but a very rough and general estimation would be in the order of $100 \mathrm{~km} \times 200 \mathrm{~km}$. The annual number of tornados occurring in Japan is estimated at 26, excluding waterspouts and other SLSs (JMA Tornado Database, 2016), and 3 typhoons strikes every year. Thus, damaged areas caused by typhoons are around 15,000 times larger than those caused by tornados. The social and economic losses caused by typhoons are much higher than those caused by tornados, but the media prefer to show images and videos of funnel-shaped clouds of tornados taken by commonly used cell phones, which maximize the impressions of viewers. Thus, people misunderstand the importance or social impacts of typhoon and tornado disasters.

\section{REPEATED DAMAGE DUE TO NATURAL HAZARDS}

It is estimated that $70-80 \%$ of natural hazard economic losses have been caused by strong wind hazards and related water hazards (Cermak, 1993; Kareem et al., 2008; Tamura, 2009; Tamura and Cao, 2011; Munich, 2015). Almost 80\% of insured losses have been caused by wind storms only, and more than $90 \%$ have been caused by wind and water hazards (Munich, 2014). The majority of strong wind storms are accompanied by heavy rain and storm surges, e.g., Hurricane Katrina, 2005, in the US and Cyclone Nargis, 2008, in Myanmar, and to cope with the combined effects of such multi-hazards of wind and water is a pressing issue. Fire, snow, hail, and so on can also be strongly affected by winds, and the combined effects of those events should also be considered.

The majority of buildings damaged by strong winds are nonengineered wooden houses and low-rise steel-frame buildings. As mentioned before, the annual number of tornados in Japan is 26 , while the total number of SLSs reported every year including waterspouts, downbursts and others is 64 . The number of US tornados is estimated at around 1,000-1,200. However, considering the more than 20 times difference between the land areas of the two countries, the probability of tornado events in Japan is comparable with that in the US. Even so, the probability of a particular individual building encountering a tornado is very low: 40,000-year-recurrence level on average in Japan and 230,000-year-recurrence level for strong tornados such as F2 or more in the US (Tamura et al., 2008). This low probability has resulted in the fact that tornado actions are largely ignored even in design of high-risk facilities such as nuclear power plants, LNG tanks, and industrial waste disposal facilities, and also for highly important facilities such as data centers. There are piles of emerging issues to be solved related to SLSs.

In the concluding remarks in post-wind-disaster investigation reports, the following are commonly said: 
- The majority of damage is to roofs and windows;

- Cladding and component damage initiate overall building damage;

- Topographic effects and debris effects are significant.

Thus, by only reading the concluding remarks, you would not be able to identify when the report was written, 1975, 1991, or 2014. The same things are repeated without any essential improvement.

These difficulties in coping with natural hazards including wind hazards result from the fact that the performance validation of buildings and structures against devastating rare events of several decades-, hundred-, or thousand-year-recurrence level have been made only by ambiguous estimation from incidentally occurring damage marks, and is like groping in the dark. The main problem is that performance evaluations done to date are inadequate.

\section{DEMAND AND NECESSITY FOR FULL-SCALE TESTS}

In order to solve those difficult problems by improving the performance of infrastructures, we need to construct a large FSSS that can contain full-scale buildings and simultaneously generate meteorological events including strong wind, fire, rain, snow, hail, and solar heating, and we need to examine the performance of cladding/components and main frames of buildings. It is not possible to make an ordinary boundary layer wind tunnel large, and new devices are required for simulating nature and typical characteristics of typhoon winds and/or tornados by using actively controlled multiple fans and/or spires such as the Insurance Institute for Business and Home Safety (IBHS) Research Center (2010) in the US and the WindEEE Dome (2013) of the Western University in Canada. We could then conduct efficient full-scale investigations under controlled conditions for saving lives and maintaining the integrity of buildings, structures, and other infrastructures from devastating meteorological hazards with recurrence periods of several decades, or hundreds, or thousands of years.

It is interesting that the University of Florida (UF) established the Storm Protection Laboratory in 1952. Since then, they have consistently been concentrating their interest on performance evaluation of houses and buildings during strong wind events. The UF was recently equipped with a Spatiotemporal Pressure Loading Actuator and a Muti-Axis Wind Load Simulator, so they can now do full-scale tests applying realistic fluctuating wind loads on mainly parts of buildings.

Pioneer works using a large-scale wind tunnel facility to investigate the performance of building parts, low-rise houses, automobiles, and so on have been made by the Jules Verne Climate Wind Tunnel at Centre Scientifique et Technique du Bâtiment in France, since 1998 (Flamand, 2015). The maximum wind speed is $80 \mathrm{~m} / \mathrm{s}$, and $200 \mathrm{~mm} / \mathrm{h}$ precipitation and $200 \mathrm{~mm} / \mathrm{h}$ equivalent snow fall can be supplied. Combined effects of wind, snow, rain, and solar heating can be examined in full-scale conditions.

The International Hurricane Research Center was established in 1996 in Florida International University, and they constructed a 2-fan Wall of Wind (WOW) in 2005 and developed a 12-fan WOW in 2011, which can simulate the combined effects of wind and rain. The aim of this facility was mainly focused on full-scale tests to determine the performance of buildings.

Similar to UF, full-scale tests using PLA and reaction frames have been conducted in the "Three Little Pigs" Project by the University of Western Ontario (UWO) (Kopp et al., 2008). Realistic fluctuating external pressures obtained from scaled wind tunnel tests can be applied to full-scale buildings using multi-chamber pressure test methods.

As mentioned already, the IBHS Research Center in the US constructed a Storm Generator with 105 actively controlled fans in 2010 . The test chamber is $44.2 \mathrm{~m} \times 44.2 \mathrm{~m}$ in plan and $18.3 \mathrm{~m}$ high. The IBHS Storm Generator can simulate the combined effects of wind, rain, hail, and fire. The maximum wind speed is $53 \mathrm{~m} / \mathrm{s}$, corresponding to Category 3 hurricanes. Full-scale two-story wooden houses can be blown off. The proposal of FSSS and MHSP to SCJ (SCJ, 2014) owes a lot to the idea of this IBHS Storm Generator. The WindEEE Dome was established in 2013 in the UWO in Canada (Hangan, 2015). This is a very unique facility that can generate various types of flow fields including uniform straight winds, ABL winds, shear flows, downbursts, tornados, and so on, using 106 individually controlled fans. Storm systems $5 \mathrm{~m}$ in diameter can be generated with $2 \mathrm{~m} / \mathrm{s}$ translational speed.

\section{OUTLINE OF FSSS AND MHSP}

Full-scale storm simulator proposed to SCJ (SCJ, 2014) should contain two- or three-story full-scale houses in its test chamber, because the majority of economic losses in Japan due to windinduced damage to buildings are to such low-rise wooden houses. Combined effects of multiple meteorological hazards such as wind, rain, snow, hails, solar heating, and fire should be tested to check the integrity and performance of claddings/components and structural frames. The test chamber part is $50 \mathrm{~m} \times 50 \mathrm{~m}$ in plan and $25 \mathrm{~m}$ high, and an inlet passage part and an outlet passage part are smoothly connected to the test chamber, without sudden changes in sectional shape. The maximum wind speed should be higher than $80 \mathrm{~m} / \mathrm{s}$, and the rain and snow intensity should be more than $200 \mathrm{~mm} / \mathrm{h}$. FSSS should generate different types of extreme winds such as straight typhoon winds and tornadic winds by combining active type and passive type flow generators. The most important target is ABL flows with vertical shear reproducing extreme typhoon winds. The stronger semicircular parts of tornadic flows with translational velocity, which cause the majority of damage areas due to tornados, should also be generated. Unsteady aerodynamic effects on buildings due to a sudden increase in wind speed should also be simulated, because these effects commonly appear in SLSs. This facility is mainly designed for performance tests on buildings/structures and their parts; load evaluation is not the main focus. The wind speeds should be very high for all types of extreme winds, and the treatment and control of debris due to failure of building/ structures are important. Therefore, fans or machines for generating flows should not be located downstream of models, so a push-on-type wind tunnel system should be adopted. For these 
purposes, 160 actively controlled fans might be necessary, and the required electric power is estimated at $90 \mathrm{MW}$. Figure 11 shows a schematic image of FSSS and MHSP (Tamura, 2015), and Figure 12 shows an example of the results of a study on a passive type flow generator simulating a part of translational tornadic winds (Phuc et al., 2016).

It should also be useful for education and enlightenment activities for DRR, because those quite rare events cannot be experienced in the life-time of individuals, and it is almost impossible to make good use of the experience gained in emergencies. Therefore, FSSS is also used as the MHSP, which should be open to the public. The MHSP has functions of a hands-on-type Science Museum, Research Institute, and a Training and Education Center related to DRR activities.

\section{ACADEMIC AND SOCIAL SIGNIFICANCE}

Studies on wind-resistant design of buildings and structures have mainly focused on improving the performance of main frames, and building standards and codes contain plenty of pages of provisions related to this, and they of course have contributed significantly to society in realizing safer and habitable tall- or super-tall buildings and long-span structures. However, windinduced damage has been done to non-engineered buildings, for which appropriate structural design cannot be made, and human losses have been caused by damage to these kinds of buildings. In particular, the majority of wind-induced building damage has been triggered by failures of claddings and components, and it is difficult to check their performance or resistance against wind actions in wind-resistant design.

It is commonly true anywhere in the world that what we can do about extremely strong typhoons, devastating tornados, heavy snow, heavy rain and so on with a recurrence periods of several decades/hundred/thousand years is limited to observing various marks of incidentally and randomly occurring damage due to an unexpected event at any moment at any unpredicted place, under different and limited external conditions, resulting in many fatalities and huge economic and social losses. Therefore, it is almost impossible to accurately determine the physical relation of external actions and the resultant behaviors of buildings and
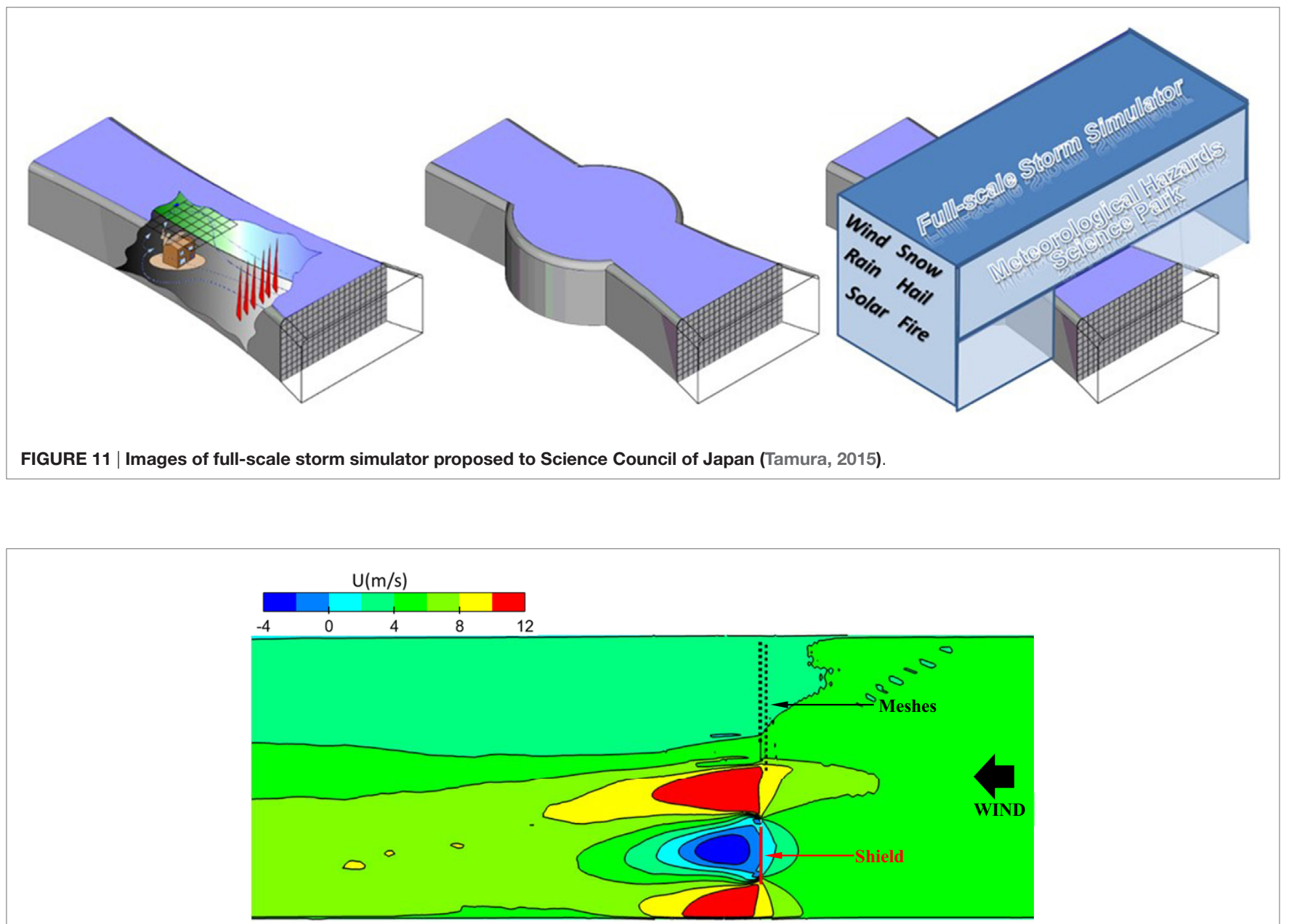

FIGURE 12 | An example of mean wind speed distribution obtained by study on passive type horizontal transverse shear flow generator (Phuc et al., 2016). 


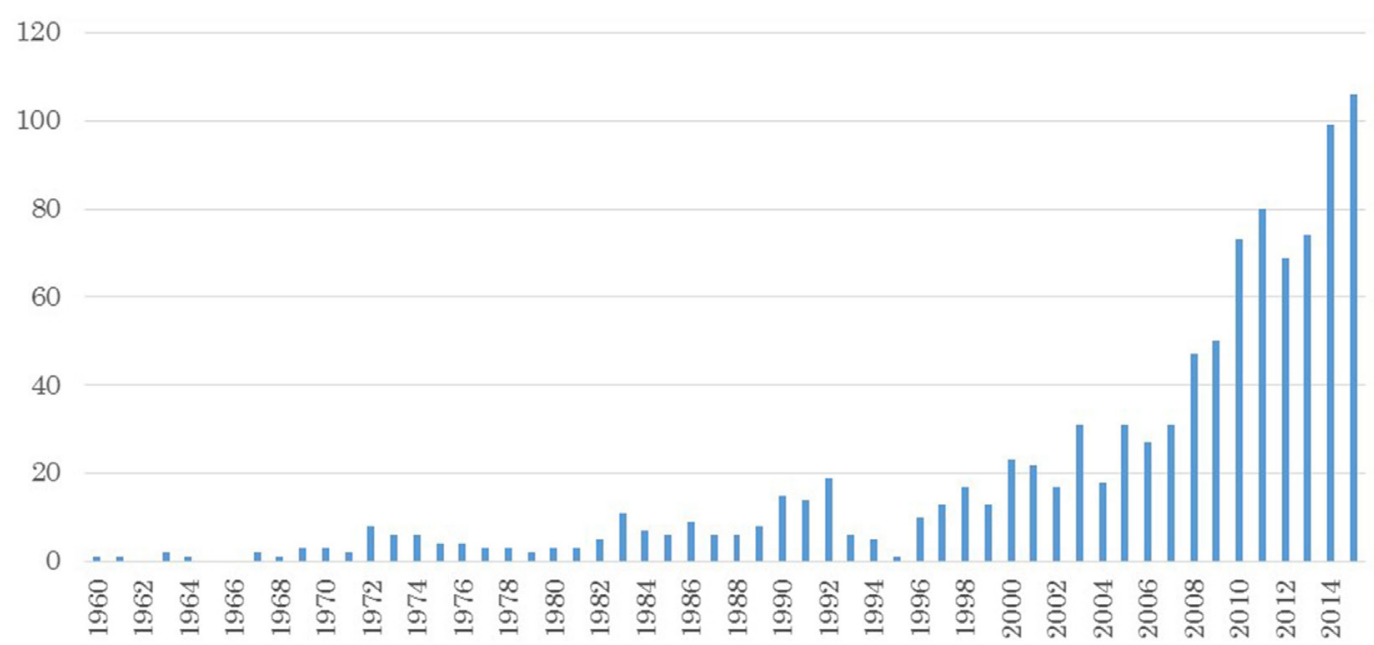

FIGURE 13 | Yearly variation of buildings $200 \mathrm{~m}$ or taller completed each year from 1960 to 2015 around the world (based on CTBUH, 2015).

structures. There has been little clarification of external actions of such extreme events on buildings and structures, and the failure mechanisms of building systems and similar disasters have been repeated.

For example, the recent development of wind engineering methods and technologies has significantly contributed to realization of tall and super-tall buildings or long- and superlong-span roof structures and bridges, as shown in Figure 13 (CTBUH, 2015). However, they do not seem to have contributed to reduction in WRD risk around the world, as indicated in Figure 14 (Munich, 2014), which clearly demonstrates the recent significant increase in the number of wind storms and floods. As is well known, strong typhoons, cyclones, and hurricanes have almost always been accompanied by heavy rain and storm surges, and wind hazards and water hazards can occur simultaneously, and the majority of devastating disasters caused by strong wind events are due to the combined effects of wind hazards and water hazards, which are expediently called "wind-related disaster" in this paper.

There are many methods for evaluating the performance of building materials and systems including pressure chambers giving repeating and fluctuating pressures on claddings and components. However, they are limited to providing specified pressures given beforehand and cannot realize the entire flow field creating the fluctuating pressure field, which essentially varies spatiotemporally and changes with the progress of the deformation of or damage to claddings, components, and partial or whole building systems. In order to check the performance of a building partially or entirely, we should follow the fracture process of the complex system of the building consisting of various materials and members including claddings, components, sub-frames, main frames, and foundations. The fracture process cannot be tested by a scaled model or numerical calculations.

The similarity laws for aerodynamic phenomena due to winds have been more or less established, and wind loading

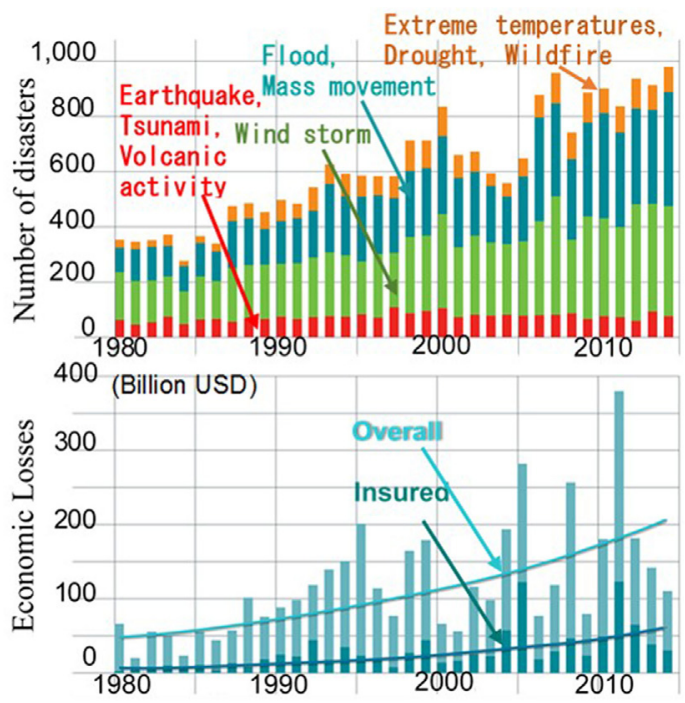

FIGURE 14 | Yearly variations of number of disasters and economic losses during 1980-2014 (Munich, 2014).

effects can be evaluated using scale models. Reynolds number effects cannot be perfectly solved, especially for structures with curved surfaces and for local peak pressures acting on roof corners. However, the majority of buildings have edged corners, and the Reynolds number effects are not so serious. However, the similarity laws are very difficult to satisfy using scale models when we consider the combined effects of two different kinds of meteorological phenomena such as wind and snow, or wind and fire, and so on. The similarity law can be satisfied for an individual phenomenon using a scale model, but it is quite difficult for two different phenomena combined, and almost impossible in many cases. Therefore, full-scale tests are required for such combined effects. 
In order to overcome these difficulties, there is no other way than to conduct full-scale tests using a full-scale model. That's why a FSSS should be constructed. An FSSS can resolve the following problems that traditional wind tunnel tests using scaled models cannot achieve the following:

- Performance of entire buildings/structures and parts including fracture progress

- Combined effects of wind, snow, rain, hail, solar heating, and fire

- Reynolds number effects.

An FSSS can efficiently provide appropriate solutions for systematically controlled cladding, components, structural and building systems, construction methods, and so on, and will perform well in modeling several decades-, hundred-, or thousandyear-recurrence rare events, in a timely manner.

Consequently, we can make following paradigm shifts:

- From indirect understanding of phenomena to direct understanding;

- From a single external action to multiple external actions; and

- From load estimation to performance estimation.

Thus, a lot of break-through researches can be made over a wide range of academic fields and significant developments in relevant industries can be promised, as well as significant impacts on the DRR. Significantly improved performance of buildings and structures, power generation systems, transmission facilities, agricultural facilities, fishery facilities, and so on will have widespread effects on society, and contribute to construction of a sustainable and resilient civilian world.

Almost 45 billion USD, 27 billion USD, and 24 billion USD are lost every year in the US, China, and Japan, respectively, due to natural hazards, as shown in Figure 15 These losses have been accumulated year by year and have been deep body blows to society. We should note that the hot spot of economic losses is in developed countries. If we could make a $2 \%$ reduction in economic losses by FSSS construction and efficient operation, 900 million USD, 540 million USD, and 480 million USD would be saved every year, and one or two decades accumulations would result in 9-18 billion USD, 5-11 billion USD, and 5-10 billion USD benefits to the US, China, and Japan, respectively.

This kind of facility will also have some strategic advantages by taking leadership in the following:

- Development of building materials, and structural and construction methods suitable for each country;

- Development of building materials, and suitable structural and construction methods for developing countries such as in the Asian region;

- Aid to developing countries in providing integrated network infrastructures;

- Foreign market penetration for DRR business; and

- Highest level of DRR research and education.

\section{CONCLUDING REMARKS}

Based on past discussions and the current status of natural hazards and hazard-induced disasters, difficulties in using scale models to evaluate the performance of buildings and structural systems including fracture processes of members, claddings, and components; difficulties in satisfying similarity laws for scale models in case of combined effects of multiple hazards such as wind and snow and so on; and the fact that enormous economic losses have accumulated in Japan and other countries; and so on have been recognized. Human and economic losses due to meteorological hazards have been significant. The hot spots of human losses are in developing countries such as South Asia, but the hot spots of economic losses are in developed countries such as the US, Japan, and China. Recently, the number of devastating

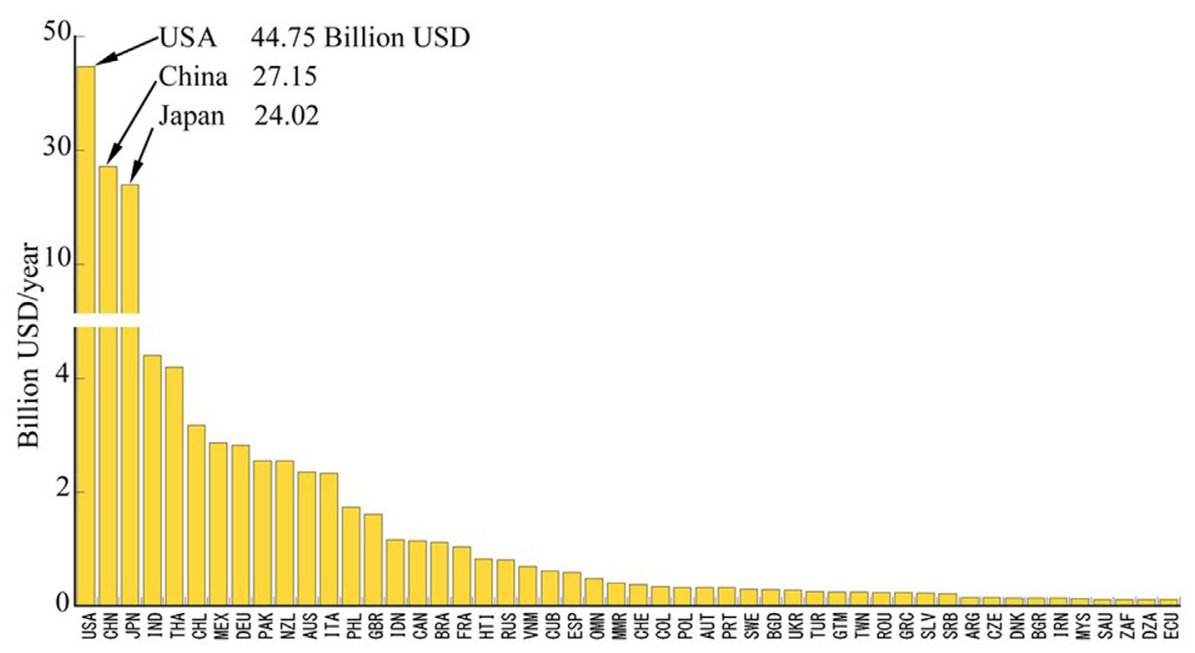

FIGURE 15 | Annual economic losses in each country due to all natural hazards from 2005 to 2014 (CRED, 2015) 
disasters due to meteorological hazards has been increasing because of rapid urbanization or other reasons.

It has been demonstrated that full-scale test facilities such as FSSS and MHSP to check the performance of buildings and structures are required to minimize the effects of disasters due to natural hazards.

Incidentally, the fire insurance premium rate (FIPR) in Japan has increased by $2-4 \%$ since October 2015 . The main reason for this increase is the recent significant increase in insurance payments due to increase in the effects of disasters induced by wind storms including explosive low-pressure systems, strong typhoons, tornados, and so on. The increase in FIPR may solve the economic concerns of insurance companies, but it cannot solve the social problems of the huge accumulating economic losses and strongly hypothesized future amplification of this increasing trend due to climate change effects.

Thus, there is a strong need for full-scale facilities, and they should have the highest priority from the viewpoint of national resilience policies of governments in the Asian region.

\section{REFERENCES}

Blake, E. S., Landsea, C. W., and Gibney, E. J. (2011). The Deadliest, Costliest, and Most Intensive United States Tropical Cyclones from 1851 to 2010 (and Other Frequently Requested Hurricane Facts). NOAA Technical Memorandum NWS NHC-6.

Brewick, P., Divel, L., Butler, K., Bashor, R., and Kareem, A. (2009). "Consequences of urban aerodynamics and debris impact in extreme wind events," in Proceedings of the 11th Americas Conference on Wind Engineering, San Juan, Puerto Rico, June 22-26, 2009. p. 17.

Brunkard, J., Namulanda, G., and Ratard, R. (2008). Hurricane Katrina deaths, Louisiana, 2005. Disaster Med. Public Health Prep. 2, 215-223. doi:10.1097/ DMP.0b013e31818aaf55

Cermak, J. E. (1993). Wind Engineering - Engineering for Wind Damage Mitigation, ASCE Structures Congress '93. Irvine, CA: Structural Engineering in Natural Hazards Mitigation, 37-58.

CRED. (2015). Centre for Research on the Epidemiology of Disasters. Available at: http://www.cred.be/

CTBUH. (2015). CTBUH Year in Review: Tall Trends of 2015, and Forecasts for 2016. The Council on Tall Buildings and Urban Habitat.

DMB. (2009). Governance and Policy Making in the Context of Disaster Management, Disaster Management Bureau, Ministry of Food and Disaster Management, Government of the People's Republic of Bangladesh, Bangladesh Disaster Preparedness Center, Proceedings of the International Forum on Tornado Risk Reduction for Bangladesh - To Cope with Neglected Severe Disasters December. Dhaka, Bangladesh: 13-14.

Flamand, O. (2015). Simulating Climate in Wind Tunnel: Why Do It at Full Scale? IAWE Public Forum "Necessity and Efficiency of Large-Scale Facilities for WindRelated Disaster Risk Reduction", The 3rd UN World Conference on Disaster Risk Reduction. Sendai, Japan.

Hangan, H. (2015). Reducing Vulnerability to Non-Synoptic Winds. The WindEEE Dome, IAWE Public Forum "Necessity and Efficiency of Large-Scale Facilities for Wind-Related Disaster Risk Reduction", The 3rd UN World Conference on Disaster Risk Reduction. Sendai, Japan.

JMA Tornado Database. (2016). Japan Meteorological Agency. Available at: http:// www.data.jma.go.jp/obd/stats/data/bosai/tornado/

Kareem, A., Kijewski-Correa, T., Tamura, Y., and Modeling, N. (2008). Next Frontiers of Innovation, Discovery and Learning in Wind Engineering: A Cyberinfrastructure Perspective, The 3rd International Symposium on Wind Effects on Buildings and Urban Environment (ISWE3). Tokyo, Japan: The 21st Century COE Program, 1-17.

Kopp, G. A., Morrison, M. J., Gavanski, E., Henderson, D. J., and Hong, H. P. (2008). The 'Three Little Pigs' Project: Integration of Wind Tunnel Model Scale

\section{AUTHOR CONTRIBUTIONS}

YT: principal author, review, data collection, and discussions (70\%). KN and MM: data collection and discussions (8\%). PP: flow simulation and discussions (8\%). QY: discussions (6\%).

\section{ACKNOWLEDGMENTS}

Useful discussions were made by Prof. Yuji Hasemi from Waseda University, Profs. Yasushi Uematsu and Akashi Mochida from Tohoku University, Dr. Naoki Sakai from National Research Institute for Earth Science and Disaster resilience, and members of AIJ and JAWE Joint WG on Full-scale Storm Simulator. They are gratefully acknowledged.

\section{FUNDING}

This study is supported in part by the 1000 Talent Plan Program for Foreign Experts, China.

Tests and Full-Scale Laboratory Tests, The 3rd International Symposium on Wind Effects on Buildings and Urban Environment (ISWE3) - New Frontiers in Wind Engineering. Tokyo, Japan.

Munich, R. (2014). Munich Re Group, Topics Geo 2014. Munich, Germany: Munich Re Group.

Munich, R. (2015). Munich Re Group, Topics, Annual Review. Munich, Germany: Natural Catastrophes.

NDRRMC. (2014). National Disaster Risk Reduction and Management Council. SitRep No. 92 Effects of Typhoon Yolanda, Haiyan.

Niino, H., Fujitani, T., and Watanabe, N. (1997). A statistical study of tornadoes and waterspouts in Japan from 1961 to 1993. J. Clim. 10, 1730-1752. doi:10.1175/1520-0442(1997)010<1730:ASSOTA > 2.0.CO;2

Nishimura, H., Okuda, Y., and Tamura, Y. (2005). High Wind Damage to Buildings in Japan by Typhoons in 2004, Proceedings of the 6th Asia-Pacific Conference on Wind Engineering. Seoul, Korea: 2935-2944.

Phuc, P. V., Kikuchi, H., Maruyama, T., Matsui, M., and Tamura, Y. (2016) A Numerical Study on a Generation System of Tornado Flow Field Using a Boundary Layer Wind Tunnel, Summaries of Technical Papers of Annual Meeting, Architectural Institute of Japan, Structures I, 20070. 139-140.

SCJ. (2014). Recommendations: The Academic Master Plans 2014 of Large Research Facilities and Large Research Projects, Subcommittee on Evaluation of Academic Large Research Projects, Scientists Committee. Japan: Science Council of Japan.

Sanada, Y., Tamura, Y., Narafu, T., Shimizu, T., and Mita, N. (2015). Damage to building structures in Philippines due to Typhoon Haiyan. J. Wind Eng. 40, 30-39. doi:10.5359/jwe.40.30

Tamura, Y. (2009). Wind-Induced Damage to Buildings and Disaster Risk Reduction, Proceedings of the 7th Asia-Pacific Conference on Wind Engineering. Taipei, Taiwan.

Tamura, Y. (2015). IAWE Public Forum "Necessity and Efficiency of Large-Scale Facilities for Wind-Related Disaster Risk Reduction", The 3rd UN World Conference on Disaster Risk Reduction. Sendai, Japan.

Tamura, Y., and Cao, S. Y. (2011). International Group for Wind-Related Disaster Risk Reduction (IG-WRDRR), Proceedings of the 13th International Conference on Wind Engineering. Amsterdam, Netherlands: 8.

Tamura, Y., Niino, H., Suzuki, O., Maki, M., Maeda, J., Matsumoto, M., et al. (2008). Research Report: Characteristics and Prediction of Tornadoes and Countermeasures (PI: Tamura, Y.), Promotion of Swift Administrative Response for Important Policy Issues, 2007FY Special Coordination Funds for the Promotion of Science and Technology. Japan Science and Technology Agency, 486.

Tamura, Y., Kobayashi, F., Suzuki, O., Uematsu, Y., and Okuda, Y. (2012). "Air chapter 3: typhoon and tornado risk management," in Environmental Disaster 
Linkages, Community, Environment and Disaster Risk Management, Vol. 9, eds R.Shaw and P.Tran (Emerald Group), 35-60.

Tamura, Y., Ohkuma, K., Sakamoto, I., Yagi, K., Okuda, Y., Ohno, H., et al. (2005). Lessons from Wind-Induced Damage to a Long-Span Steel Roof Due to Two Typhoons in 2004, Proceedings of the 6th Asia-Pacific Conference on Wind Engineering. Seoul, Korea: 2907-2916.

Zaw, W. (2009). Cyclone Nargis in Myanmar, May 2, 2008, Proceedings of the Cooperative Actions for Disaster Risk Reduction (CADRR), The 4th International Symposium on Wind Effects on Buildings and Urban Environment (ISWE4). Tokyo: UN University.
Conflict of Interest Statement: The authors declare that the research was conducted in the absence of any commercial or financial relationships that could be construed as a potential conflict of interest.

Copyright $\odot 2017$ Tamura, Nishijima, Matsui, Phuc and Yang. This is an open-access article distributed under the terms of the Creative Commons Attribution License (CC $B Y)$. The use, distribution or reproduction in other forums is permitted, provided the original author(s) or licensor are credited and that the original publication in this journal is cited, in accordance with accepted academic practice. No use, distribution or reproduction is permitted which does not comply with these terms. 